\title{
Sleep may not benefit learning new phonological categories
}

\section{Gregory Collet ${ }^{1,2,3}$, Rémy Schmitz ${ }^{4}$, Charline Urbain ${ }^{4}$, Jacqueline Leybaert ${ }^{3}$, Cécile Colin ${ }^{2}$ and Philippe Peigneux ${ }^{4 *}$}

\author{
${ }^{1}$ Fonds National de la Recherche Scientifique, Bruxelles, Belgium \\ 2 Unité de Recherche en Neurosciences Cognitives, Université Libre de Bruxelles, Bruxelles, Belgium \\ ${ }^{3}$ Laboratoire Cognition Langage Développement, Université Libre de Bruxelles, Bruxelles, Belgium \\ ${ }^{4}$ Unité de Recherche en Neuropsychologie et Neuroimagerie Fonctionnelle, Université Libre de Bruxelles, Bruxelles, Belgium
}

\section{Edited by:}

Mehmet Y. Agargün, Yuzuncu Yil

University, Turkey

\section{Reviewed by:}

Sara J. Aton, University of

Pennsylvania, USA

Axel Steiger, Max Planck Institute of

Psychiatry, Germany

*Correspondence:

Philippe Peigneux, Unité de

Recherche en Neuropsychologie et

Neuroimagerie Fonctionnelle,

Université Libre de Bruxelles, Avenue

F.D. Roosevelt 50, CP191, Bruxelles

B-1050, Belgium.

e-mail:philippe.peigneux@ulb.ac.be
It is known that sleep participates in memory consolidation processes. However, results obtained in the auditory domain are inconsistent. Here we aimed at investigating the role of post-training sleep in auditory training and learning new phonological categories, a fundamental process in speech processing. Adult French-speakers were trained to identify two synthetic speech variants of the syllable /da/ during two 1-h training sessions. The 12-h interval between the two sessions either did (8 p.m. to 8 a.m. \pm 1 h) or did not (8 a.m. to 8 p.m. $\pm 1 \mathrm{~h}$ ) included a sleep period. In both groups, identification performance dramatically improved over the first training session, to slightly decrease over the 12-h offline interval, although remaining above chance levels. Still, reaction times (RT) were slowed down after sleep suggesting higher attention devoted to the learned, novel phonological contrast. Notwithstanding, our results essentially suggest that post-training sleep does not benefit more than wakefulness to the consolidation or stabilization of new phonological categories.

\section{Keywords: sleep, auditory training, identification, new phonological categories}

\section{INTRODUCTION}

In the last two decades, evidences have accumulated to suggest that sleep participates in the consolidation of recently learned information (Diekelmann et al., 2009; Peigneux and Smith, 2010), both for declarative (Born and Wilhelm, 2012) and non-declarative (e.g., Plihal and Born, 1997, 1999) memories. Regarding the latter domain, many studies have found that sleep provides an advantage in consolidating skills and habits (i.e., a set of perceptual, motor, and cognitive abilities gradually acquired through repeated practice). For instance, it was found that post-training sleep boosts subsequent performance on non-verbal motor (e.g., Walker et al., 2002; Walker et al., 2003; Hotermans et al., 2006), perceptual visual (e.g., Karni et al., 1994; Gais et al., 2000; Stickgold et al., 2000a,b), and perceptivo-motor tasks (Smith and MacNeill, 1994; Maquet et al., 2000, 2003; Peigneux et al., 2003). Notwithstanding, sleepdependent improvement in skills and habits cannot be generalized across modalities, as contradictory results have been reported in the auditory domain, in which we will focus hereafter.

Since a long time, studies showed that the perception of nonnative phonological contrasts can be improved after a short period of auditory training using identification and discrimination tasks. This improvement in perception have been extensively studied at the behavioral level both in adults (McClaskey et al., 1983; Jamieson and Morosan, 1986; Flege, 1989; Bradlow et al., 1997) and infants (Maye et al., 2002, 2008), as well as at the cerebral level using electrophysiological (Tremblay et al., 1997, 1998, 2001), functional, and structural brain imaging techniques (Golestani et al., 2002, 2007; Golestani and Zatorre, 2004). Associations between speech processing abilities and brain morphometry or myelination, together with consistent improvement in perceptual abilities and/or changes in the underlying brain activity after short training periods emphasize the importance of brain plasticity during the auditory training phase.

Beside practice-related changes during wakefulness, several studies showed that it is possible to train auditory discrimination abilities in sleeping newborns (Cheour et al., 2002; Sambeth et al., 2008), showing that plastic processes are not on hold during sleep. Furthermore, other studies have suggested that posttraining offline sleep periods may play an important role in the development and consolidation of speech perception abilities. For instance, Fenn et al. (2003) trained subjects to discriminate phonological categories within a computer-generated speech. After $12 \mathrm{~h}$ of wakefulness, training-related gains in performance significantly decreased as compared to $12 \mathrm{~h}$ including a night of sleep. Furthermore, after a night of sleep in the group kept awake $12 \mathrm{~h}$ after training, recognition performance was back to immediate posttraining levels. All together, these results suggest a sleep-dependent consolidation process capable of restructuring previously learned auditory skills. Using a pitch discrimination task, Gaab et al. (2004) similarly found performance improvement after a night of sleep but not after equivalent periods of wake.

Notwithstanding, others failed to disclose sleep-dependent changes in auditory learning abilities. Indeed, Gottselig et al. (2004) found performance improvement in auditory tone sequence learning both after restful waking and sleep but not after busy waking, suggesting that it is actually ongoing interference 
from sensory input and other learning that prevents consolidation during active wakefulness. Likewise, Roth et al. (2005) trained participants to identify vowel-consonant combinations against a background noise; they found that performance improvement did not become effective until $4 \mathrm{~h}$ post-training, and actually developed similarly over a $12-\mathrm{h}$ period either awake or including sleep. Hence, these studies disclosed sleep-independent consolidation by showing that time spent in the waking state is sufficient to improve performance. Still, it must be noticed that this conclusion only holds at the behavioral level. Atienza et al. (2004) also found similar improvements in auditory discrimination performance after sleep and wakefulness, whereas evoked-related potentials differentially developed as a function of the availability of post-training sleep. Indeed, sleep deprivation after training prevented the development of brain responses associated with automatic shifts of attention to unexpected stimuli.

In the present behavioral study, we investigated the potential role of post-training sleep in voicing perception, a fundamental auditory process in speech processing. Voicing perception relies mainly on the time interval between the release from stop closure and the onset of laryngeal pulsing, also know as the Voice Onset Time (VOT; Lisker and Abramson, 1964). To test the hypothesis of sleep-dependent learning in voicing perception, adult Frenchspeaking participants learned to categorize new phonological French voicing contrasts during two 1-h training sessions separated by a 12-h interval either spent busy awake or including sleep. Results mainly indicate that, in line with prior studies, auditory perception abilities similarly improve in the sleeping and busy waking conditions, bringing into question the hypothesis that sleep plays a specific role in the consolidation of voicing perception skills.

\section{MATERIALS AND METHODS PARTICIPANTS}

Participants $(n=20)$ were $18-38$ years old native French-speakers with no reported history of auditory or language disorders. All were naive to the experimental procedure and had not participated in similar experiments before. They were randomly assigned to either the busy waking ( 10 participants; mean age $=20.9 \pm 6.06$; eight females) or the sleeping group (SG; 10 participants; mean age $=19.7 \pm 2.7$; seven females). All participants had intermediate chronotype (range 37-62), as measured by the MorningnessEveningness Questionnaire (Horne and Ostberg, 1976). Laterality Quotient (Oldfield, 1971) indicated three left handed participants in the busy waking group (BWG) and two left handed participants in the SG.

\section{MATERIAL}

Stimuli were /alveolar stop + neutral vocoid/ syllables generated by a parallel formant synthesizer (Klatt, 1980) issued from a /d $\partial$ t $\partial$ / VOT continuum, from -90 to +90 ms VOT provided by Carré (2004). The VOT continuum means that perception of the generated syllable will vary from $/ \mathrm{d} \partial /$ to $/ \mathrm{t} \partial /$ as a function of the time interval (e.g., $90 \mathrm{~ms}$ ) between the release from stop closure to the onset of laryngeal pulsing but also the occurrence of these two events ( + when the release from stop closure occurs before, e.g.,
$+90 \mathrm{~ms}$, and - when the release from stop closure occurs after the laryngeal pulsing onset, e.g., $-90 \mathrm{~ms}$ ).

In this study, only two different VOT values were used: $-20 \mathrm{~ms}$ VOT and $-40 \mathrm{~ms}$ VOT. The onsets frequencies of the F1, F2, and F3 transitions were respectively of 200,2200 , and $3100 \mathrm{~Hz}$ and the steady state formant frequencies were 500,1500 , and $2500 \mathrm{~Hz}$, respectively. Negative VOT values were synthesized with periodic energy ( $60 \mathrm{~dB}), \mathrm{F} 1$ bandwidth at $50 \mathrm{~Hz}$, and F2 and F3 bandwidths both at $600 \mathrm{~Hz}$. The $F_{0}$ value was constant at $120 \mathrm{~Hz}$ and the overall duration of each stimulus was $200 \mathrm{~ms}$.

Preliminary studies showed that these two stimuli are perceived as /d $\partial$ / by French-speaking children and adults (Medina et al., 2010; Hoonhorst et al., 2011). In French, the /d $\partial-\mathrm{t} \partial /$ VOT continuum is divided into two categories at about $0 \mathrm{~ms}$ VOT, corresponding to an opposition between voiceless and voiced stops (Serniclaes, 2011). Using this material, the $-40 \mathrm{~ms}$ VOT will remain associated to the / $\mathrm{d} \partial /$ category throughout training, whereas a mismatch in perception will progressively develop for the $-20 \mathrm{~ms}$ VOT. Indeed, training and systematic feedback will force and reinforce categorization of the $-20 \mathrm{~ms}$ VOT, initially associated with the / $\mathrm{d} \partial$ / category, to the novel / $\mathrm{t} \partial$ / category. Identification tasks (pre-training, post-training, and training; see below) were programmed and presented using Matlab ${ }^{\mathrm{TM}}$ software. Stimuli were binaurally delivered through headphones (SENNHEISER HD 202), and feedback (during training sessions only) was provided on a $15^{\prime \prime}$ computer monitor located $\pm 50 \mathrm{~cm}$ from the participant's eyes.

\section{PROCEDURE}

All participants participated in two 1-h training sessions separated by a 12-h interval (Figure 1A). The BWG had the first training session in the morning ( $8 \mathrm{a} . \mathrm{m} . \pm 1 \mathrm{~h}$ ) and the second training session in the evening of the same day ( 8 p.m. $\pm 1 \mathrm{~h}$ ). In the SG, the first training session was in the evening of 1 day $(8 \mathrm{p} . \mathrm{m} . \pm 1 \mathrm{~h})$ and the second training session in the morning of the following day $(8$ a.m. $\pm 1 \mathrm{~h}$ ). At each session, an identification task took place prior and after the training session (see below; Figure 1B).

At the beginning and at the end of each 1-h session, subjective vigilance was monitored using the Karolinska Sleepiness Scale (KSS; Akerstedt and Gillberg, 1990), with which participants rated their perceived drowsiness state from one (highly awakened) to eight (highly drowsy). Objective vigilance was also monitored using the Psychomotor Vigilance Task (PVT; Dinges and Powell, 1985). In the PVT task, participants were asked to press a response key as fast as possible whenever a millisecond countdown appeared in the middle of a black computer screen. Stimuli appeared randomly within a time window ranging from 2 to $10 \mathrm{~s}$, all along a 5-min period.

Finally, sleep habits over the past month were assessed using the Pittsburgh Sleep Quality Index (PSQI; Buysse et al., 1989). Nightly sleep quality was subjectively assessed using the St. Mary's Hospital Sleep Questionnaire (Ellis et al., 1981) for the night before the experiment in both groups, and the night between the two training sessions in SG participants. Additionally, the Fatigue Severity Scale (FSS - Krupp et al., 1989) and the Epworth Sleepiness Scale (ESS - Johns, 1991) were used to control for fatigue over the week before the experiment. 


\section{A}

Busy Waking Group (BWG)
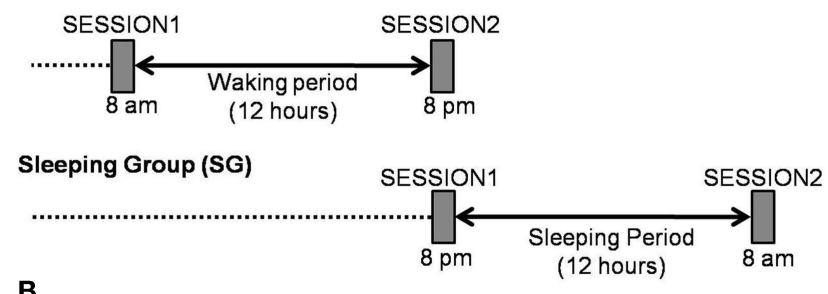

B (12 hours)

Time course for each Session

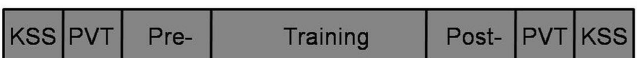

FIGURE 1 | (A) Experimental design in Busy Waking (BWG - top side) and Sleeping (SG - down side) groups. (B) Time course of the experiment within each Session: KSS, Karolinska Sleepiness Scale (Akerstedt and Gillberg,
1990); PVT, Psychomotor Vigilance Task (Dinges and Powell, 1985); Pre- and Post- correspond to identification tasks (1 block of 20 stimuli each) administered before and after the training ( 25 blocks of 20 stimuli) sessions.

\section{TRAINING}

Participants were trained using a two-alternative forced choice identification task. At each session (Figure 1B), 25 blocks of 20 stimuli were presented. Each block was composed of 10 random presentations of each $-20 \mathrm{~ms}$ VOT (associated to the $/ \mathrm{t} \partial /$ answer) and $-40 \mathrm{~ms}$ VOT (associated to the /d $/$ answer). For each token, participants were presented with single sounds; they had then to decide whether they heard a /d $\partial /$ or a /t $\partial /$ by pressing the appropriate response key on the keyboard. After each answer, a green (correct response) or a red (false response) reinforcement screen appeared on the computer to provide feedback on perception accuracy. Order of stimuli was counterbalanced between participants, sessions (session 1 and session 2) and blocks within a session.

\section{PRE- AND POST-TRAINING}

To assess the evolution of perception abilities, an identification task was administered before (pre-) and after (post-) training at both sessions (Figure 1B). Like in training, participants were presented with single sounds and had to decide whether the presented stimulus was a / $\mathrm{d} \partial /$ or a / $\mathrm{t} \partial /$ by pressing the appropriate response key on the keyboard. After each answer, there was a $2 \mathrm{~s}$ delay before the next trial was initiated. Contrary to training however, no feedback was provided after the participant's answer. Each identification task comprised 20 stimuli with 10 random presentations of the -20 and $-40 \mathrm{~ms}$ VOT. Order of stimuli was counterbalanced between participants, sessions (session 1 and session 2), and blocks within a session (pre- and post-training).

\section{DATA ANALYSIS}

Training-related learning effects were analyzed separately for both training sessions using repeated measurements ANOVAs on correct identification with Practice (two levels: pre- and posttraining) and Stimulus (two levels: -20 and $-40 \mathrm{~ms}$ VOT) as within-subject factor and Group (two levels: SG and BWG) as between-subject factor. It was not possible to analyze reaction times (RTs; latency from stimulus onset to button press) since some participants failed to identify $-20 \mathrm{~ms}$ VOT as a / t $\partial /$ in pre-training.
Sleep- or Time-dependent effects were analyzed using both percentage of correct identification and RT, comparing identification performance between post-training at Session 1 and pre-training at Session 2. Repeated measurements ANOVAs were computed on either correct identification or RTs with Session (two levels: posttraining S1 and pre-training S2) and Stimulus (two levels: -20 and $-40 \mathrm{~ms}$ VOT) as within-subject factor, and Group (two levels: SG and BWG) as between-subject factor.

\section{RESULTS}

\section{SLEEP, SLEEPINESS, AND VIGILANCE PARAMETERS}

Sleep duration and latency (PSQI) were similar in BWG and SG participants (both $F<1$ ). Average sleep latency was $37 \pm 29.4 \mathrm{~min}$, and average sleep duration $7.9 \pm 0.9 \mathrm{~h}$ Likewise, fatigue (FSS: $32 \pm 8.7 ; F<1)$ and sleepiness [ESS: $11.5 \pm 4.4 ; F(1,18)=3.12$; $p>0.05$ ] scores over the week preceding the experiment were similar. For the night preceding the experiment (St. Mary's Hospital Sleep Questionnaire), sleep duration was longer in the SG $(8.63 \pm 1.4 \mathrm{~h})$ than in the BWG (average $6.65 \pm 0.96 \mathrm{~h}$ ) group $[F(1,18)=13.5 ; p=0.002]$. Average sleep duration during the night between Sessions 1 and 2 in the SG group was $6 \pm 0.96 \mathrm{~h}$.

Objective (PVT; RT) and subjective (KSS; scale score) vigilance (Table 1) parameters were analyzed using repeated measurements ANOVAs with within-subject factors Session (two levels: S1 vs. S2) and Practice (two levels: pre- vs. post-training) and betweensubject factor Group (two levels: SG and BWG). No significant main or interaction effects were found either for the PVT or the KSS, suggesting that vigilance was maintained at similar levels within participants and across groups all over the experiment (all $p>0.1)$.

\section{TRAINING-RELATED EFFECTS}

During training Session 1, identification performance drastically improved from pre- to post-training evaluation blocks for the $-20 \mathrm{~ms}$ but (as expected) not for the $-40 \mathrm{~ms}$ VOT, both in SG and BWG participants (Figure 2). During training Session 2, performance seemingly increased similarly in SG and BWG participants for both training values ( -20 and $-40 \mathrm{~ms}$ VOT). 
Statistical analysis confirmed these observations. During Session 1, Practice [pre- vs. post-training block; $F(1,18)=41.37$; $\left.p<0.0005 ; \eta^{2}=0.7\right]$, Stimulus $[-20$ vs. $-40 \mathrm{~ms}$ VOT; $F(1$, $\left.18)=70 ; p<0.0005 ; \eta^{2}=0.8\right]$ and Practice $\times$ Stimulus interaction $\left[F(1,18)=51 ; p<0.0005 ; \eta^{2}=0.74\right]$ effects were significant. Neither the Group factor nor the Stimulus $\times$ Group and Practice $\times$ Stimulus $\times$ Group interactions reached significance (all $F<1$ ). Planned comparison contrasts looking at changes from pre- to post-training blocks for each stimulus type were significant for the $-20 \mathrm{~ms} \operatorname{VOT}\left[F(1,18)=58.3 ; p<0.0005 ; \eta^{2}=0.71\right]$ but not for the $-40 \mathrm{~ms}$ VOT $(F<1)$. During Session 2, only the Practice factor reached significance $[F(1,18)=21.72 ; p<0.0005$; $\eta^{2}=0.55$; all other $\left.p>0.22\right]$.

\section{SLEEP-RELATED EFFECTS Identification scores}

As illustrated Figure 2, identification performances globally decreased for both groups and stimuli types over the 12-h interval between post-training Session 1 and pre-training Session 2 . Statistical analysis confirmed these observations in disclosing a significant Session effect only $\left[F(1,18)=16 ; p=0.001 ; \eta^{2}=0.47\right]$. Decreased performance was observed for SG and BWG groups both for $-20 \mathrm{~ms}$ VOT (Post-Session 1: $69 \pm 30.9 \%$ and Pre-Session 2: $61.5 \pm 29.6 \%$ ) and $-40 \mathrm{~ms}$ VOT (Post-Session 1: $84.5 \pm 17.6 \%$ and Pre-Session 2: $71.5 \pm 17.8 \%)$. Stimulus $[F(1,18)=3.6$; $\left.p>0.05 ; \eta^{2}=0.17\right]$ and Group $(F<1)$ factors, Session $\times$ Group $(F<1)$, Stimulus $\times$ Group $(F<1)$, Session $\times$ Stimulus $(F<1)$,

Table 1 | Psychomotor Vigilance Task and KSS results: mean reaction times and scale score ( \pm standard deviations) for each group (Sleeping and Busy Waking) at each testing/evaluation.

\begin{tabular}{llccccc}
\hline Task & Group & \multicolumn{2}{c}{ Session 1 } & & \multicolumn{2}{c}{ Session 2 } \\
\cline { 3 - 4 } \cline { 6 - 7 } & & Pre-training & Post-training & & Pre-training & Post-training \\
\cline { 3 - 4 } & & & & & & \\
PVT & SG & $306.6 \pm 29.7$ & $327.6 \pm 29.7$ & & $315.3 \pm 42.8$ & $335.2 \pm 31.6$ \\
& BWG & $306.1 \pm 31.6$ & $315.2 \pm 37.8$ & & $323.1 \pm 41.9$ & $335.4 \pm 28.6$ \\
KSS & SG & $4.2 \pm 1$ & $5.2 \pm 1$ & & $5.2 \pm 1.8$ & $5.1 \pm 1.8$ \\
& BWG & $3.9 \pm 0.9$ & $4.9 \pm 1$ & & $4.1 \pm 1.3$ & $4.8 \pm 1.3$
\end{tabular}

and Session $\times$ Stimulus $\times$ Group $(F<1)$ interaction effects were all non-significant.

\section{Reaction times}

Figure 3 illustrates overall faster RTs over the 12-h interval in pretraining Session 2 than post-training Session 1, with the exception of increased RT in the SG group for the -20 and $-40 \mathrm{~ms}$ VOT.

Statistical analyzes disclosed significant Session $\times$ Group $[F(1$, 18) $\left.=5.7 ; p<0.03 ; \eta^{2}=0.24\right]$ and Session $\times$ Stimulus $\times$ Group $\left[F(1,18)=7.3 ; p<0.02 ; \eta^{2}=0.3\right]$ interaction effects. Planned comparison contrasts looking at changes from pre- to posttraining blocks for each stimulus type were performed for each group separately. For SG participants, comparisons reached significance for the $-20 \mathrm{~ms} \operatorname{VOT}\left[F(1,9)=6.28 ; p<0.04 ; \eta^{2}=0.41\right]$ but not the $-40 \mathrm{~ms}$ VOT $(F<1)$. For BWG participants, no significant changes were observed both at -20 and $-40 \mathrm{~ms}$ VOT [respectively $F(1,9)=2.7 ; p>0.05 ; \eta^{2}=0.13$ and $F(1,9)=2.9$; $\left.p>0.05 ; \eta^{2}=0.12\right]$.

\section{DISCUSSION}

Our study aimed at determining the potential benefit of posttraining sleep in learning new phonological contrasts. To do so, we assessed learning and retention over two 1-h training sessions spaced apart by $12 \mathrm{~h}$ spent either during a busy day awake or a night including a sleep period. Results revealed strong and efficient learning in both experimental groups. Indeed, after $1 \mathrm{~h}$ of training (i.e., 25 blocks of 20 stimuli), identification scores drastically improved (about 60\%) for the new stimulus to be categorized (i.e., $-20 \mathrm{~ms}$ VOT associated to $/ \mathrm{t} \partial /$ ), whereas as expected they remained high and stable for the over learned $-40 \mathrm{~ms}$ VOT. During the second 1-h session, acquired identification abilities were relatively preserved and identification scores continued improving in all conditions (about $15 \%)$ both for the learned $(-20 \mathrm{~ms}$ VOT) and the prototypical $(-40 \mathrm{~ms}$ VOT) stimuli. These results are in accordance with the vast majority of auditory training studies, indicating that auditory perception abilities can be improved within short-term laboratory training sessions (Jamieson and Morosan, 1986; Tremblay et al., 1997, 1998, 2001; Golestani and Zatorre, 2004).
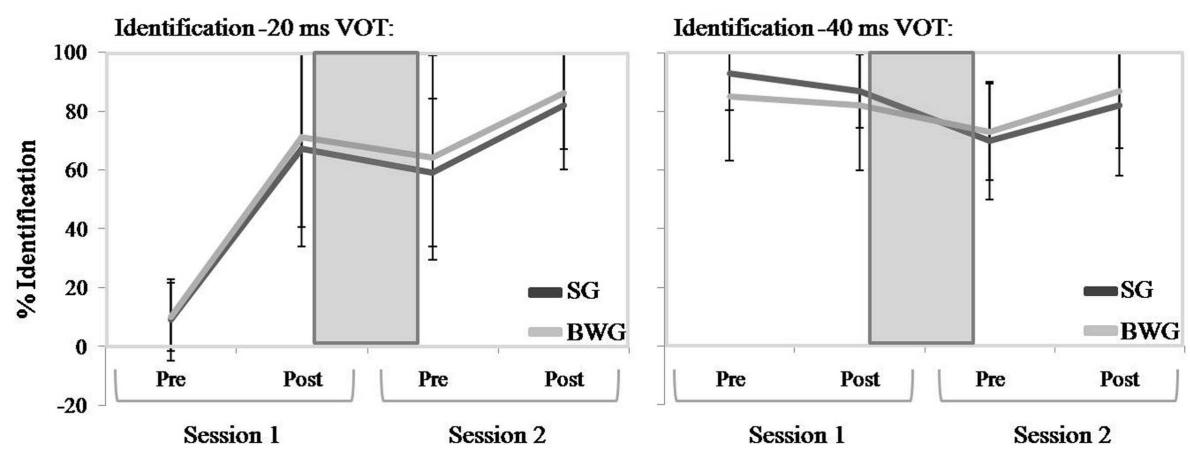

FIGURE 2 | Identification performances (\%) in Sleeping (SG; light gray) and Busy Waking Group (BWG; dark gray) groups over the four evaluations: Pre- and Post-training in Session 1 and Pre- and

Post-training in Session 2. Performance is presented separately for $-20 \mathrm{~ms}$ VOT (left) and $-40 \mathrm{~ms}$ VOT (right). The gray square on the graph represents the 12-h delay between the two sessions (either for SG or BWG). 

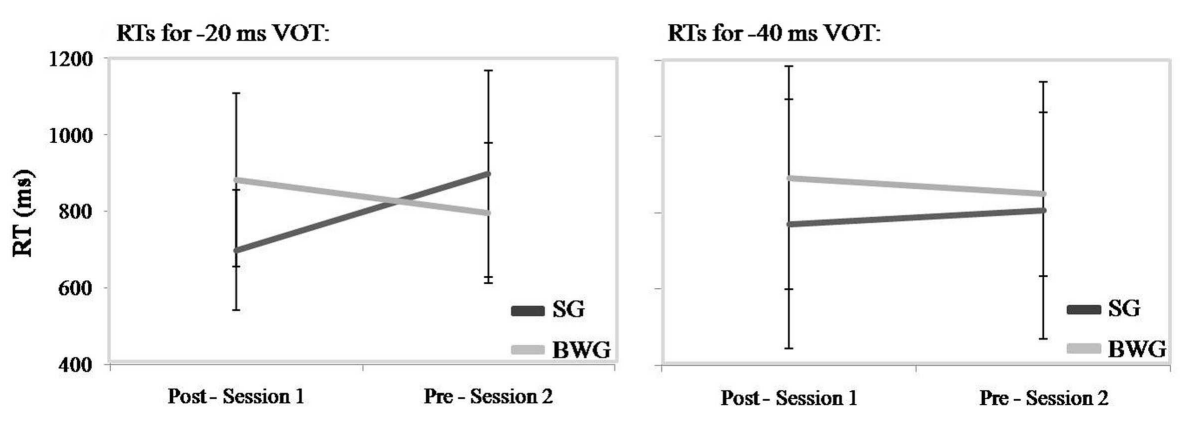

FIGURE 3 | Reaction times (RTs) in sleeping (SG; light gray) and busy waking group (BWG; dark gray) groups during identification tasks at Post-training in Session 1 (Post-Session 1) and
Pre-training in Session 2 (Pre-Session 2), separated by a 12-h offline interval. RTs are presented separately for $-20 \mathrm{~ms}$ VOT (left) and $-40 \mathrm{~ms}$ VOT (right).
To specifically assess the potential contribution of post-training sleep in offline changes in performance, a 12 -h delay separated the two training sessions, and participants were randomly assigned to either a sleeping or a BWG. Results disclosed a similar evolution from the end of the first to the beginning of the second training session, with an actual decrease in identification performance (about 10\%) for both stimuli types, although remaining significantly higher than at the beginning of training in Session 1 for the learned $-20 \mathrm{~ms}$ VOT. As it is, these results are partially in line with prior studies (Gottselig et al., 2004; Roth et al., 2005; also Atienza et al., 2004 at the behavioral level) having shown sleep-independent changes in performance. However, it should be noticed that these studies reported strong improvements in performance over a sleeping or a busy waking period, whereas our results at best indicate performance stabilization, since performance slightly decreased but still was above chance levels for the learned $-20 \mathrm{~ms}$ VOT. Still, sleep-dependent consolidation processes are not necessarily akin to performance improvement (Peigneux et al., 2005), and the fact that performance stabilized over time slightly below end-of-training levels only indicates that quantitatively similar processes are at play during post-training sleep and wakefulness periods. Also, it was recently pointed out that menstrual cycle variations might exert an influence on motor and declarative sleep-related memory consolidation in women (Genzel et al., 2012). Further studies should test whether this factor may contribute to the performance profile found in the present study using a perceptual auditory training task.

Surprisingly, beside equivalent temporal dynamics in identification performance in sleeping and waking groups, RT exhibited a differential evolution. After $12 \mathrm{~h}$ of wakefulness, RT were unchanged for both stimuli types, whereas they slowed down for the trained $-20 \mathrm{~ms}$, but not for the over learned $-40 \mathrm{~ms}$ VOT in the post-training sleep condition. One potential and straightforward interpretation for such changes occurring in opposite direction in both training groups for the $-20 \mathrm{~ms}$ VOT would be that they reflect a mere circadian effect. Indeed, inspection of Figure 3 shows that RTs are systematically slower in the morning than in the evening in both groups, although the between-session effect reaches significance in the Sleep group only. However, we believe that this interpretation is not entirely justified since no between-groups or between sessions differences are observed on the psychomotor vigilance test (Dinges and Powell, 1985), known to be highly sensitive to variations in circadian and homeostatic pressure regulatory processes (see, e.g., Schmidt et al., 2007). Also, RTs for the $-20 \mathrm{~ms}$ VOT were actually slower, not faster, in the morning than in the evening, and no session effect was observed for the $-40 \mathrm{~ms}$ VOT. Such pattern that cannot be easily explained in terms of a mere circadian effect should have affected all components equally.

In this context, another tempting explanation for this itemspecific response slowing in the $-20 \mathrm{~ms}$ VOT condition would be that conscious processing of the task was increased after sleep. It is worth noticing that slowed responses occurred for the target stimulus, where a mismatch in phonological perception was imposed by systematic feedback during training, eventually leading to the association of the target stimulus with another phonological category. Using a Number Reduction Task (NRT) in which subjects suddenly realize during practice that there is an underlying, simpler numbers transformation rule that allows to solve the problem in a straightforward manner, Wagner et al. (2004) found that not only post-practice sleep accelerated the discovery of the hidden rule, but also that RT were actually slower in the preceding trials in solver participants. According to the authors, response slowing was related to processes of search and task analysis following the presence of an incipient representation of the hidden rule. Although no rule was hidden in our paradigm and instructions were perfectly explicit, it may be that in participants having been allowed to sleep after training, a more salient and conscious representation of the voicing contrast to be learned emerged, leading to more time spent in the analysis of the stimulus. Although speculative, this interpretation might be related to the aforementioned study of Atienza et al. (2004), who found that despite a lack of sleep-dependent behavioral change in auditory discrimination performance, sleep deprivation after training prevented the development of brain responses associated with automatic shifts of attention to unexpected stimuli. Such results may suggest that post-training sleep improves the efficiency of the brain's attentional mechanisms in detecting the presence of meaningful stimuli within the environment and making them available for conscious inspection. However, such item-specific response slowing after sleep still unclear and should be investigated further. To address this question further studies should investigate whether response slowing after post-training sleep in learning novel voicing contrasts is replicable and associated with changes at the brain 
level, either in terms of electrophysiological (e.g., ERPs) or brain imaging (e.g., fMRI) responses. Indeed, it is possible for covert, non-measurable behavioral changes after sleep to be accompanied by sleep-dependent changes in the underlying cerebral activity, as previously shown in the declarative memory domain (Orban et al., 2006; Gais et al., 2007; Rauchs et al., 2008; Sterpenich et al., 2009).

To sum up, this study showed that sleep does not benefit new phonological contrast learning but it suggests emergence of a more conscious representation of the learned stimulus.

\section{REFERENCES}

Akerstedt, T., and Gillberg, M. (1990). Subjective and objective sleepiness in the active individual. Int. J. Neurosci. 52, 29-37.

Atienza, M., Cantero, J. L., and Stickgold, R. (2004). Postraining sleep enhances automaticity in perceptual discrimination. J. Cogn. Neurosci. 16, 53-64.

Born, J., and Wilhelm, I. (2012). System consolidation of memory during sleep. Psychol. Res. 76, 192-203.

Bradlow, A. R., Pisoni, D. B., AkahaneYamada, R., and Tohkura, Y. (1997). Training Japanese listeners to identify English /r/ and /l/: IV. Some effects of perceptual learning on speech production. J. Acoust. Soc. Am. 101, 2299-2310.

Buysse, D. J., Reynolds, C. F. III, Monk, T. H., Berman, S. R., and Kupfer, D. J. (1989). The Pittsburgh Sleep Quality Index: a new instrument for psychiatric practice and research. Psychiatry Res. 28, 193-213.

Carré, R. (2004). Program SyntFormVoy. Laboratoire Dynamique $d u$ Language. Lyon: CNRS.

Cheour, M., Martynova, O., Näätänen, R., Erkkola, R., Sillanpää, M., Kero, P., Raz, A., Kaipio, M.-L., Hiltunen, J., Aaltonen, O., Savela, J., and Hämäläinen, H. (2002). Speech sounds learned by sleeping newborns. Nature 415, 599-600.

Diekelmann, S., Wilhelm, I., and Born, J. (2009). The whats and whens of sleep-dependent memory consolidation. Sleep Med. Rev. 13, 309-321.

Dinges, D. F., and Powell, J. W. (1985). Microcomputer analyses of performance on a portable, simple visual RT task during sustained operations. Behav. Res. Methods 17, 652-655.

Ellis, B. W., Johns, M. W., Lancaster, R., Raptopoulos, P., Angelopoulos, N., and Priest, R. G. (1981). The St. Mary's Hospital sleep questionnaire: a study of reliability. Sleep 4, 93-97.

Fenn, K. M., Nusbaum, H. C., and Margoliash, D. (2003). Consolidation during sleep ofperceptual learning of spoken language. Nature 425, 614-616.
Flege, J. (1989). Using visual information to train foreign language vowel production. Lang. Learn. 38, 365-407.

Gaab, N., Paetzold, M., Becker, M., Walker, M. P., and Schlaug, G. (2004). The influence of sleep on auditory learning: a behavioral study. Neuroreport 15, 731-734.

Gais, S., Albouy, G., Boly, M., DangVu, T. T., Darsaud, A., Desseilles, M., Rauchs, G., Schabus, M., Schabus, V., Vandewalle, G., Maquet, P., and Peigneux, P. (2007). Sleep transforms the cerebral trace of declarative memories. Proc. Natl. Acad. Sci. U.S.A. 104, 18778-18783.

Gais, S., Plihal, W., Wagner, U., and Born, J. (2000). Early sleep triggers memory for early visual discrimination skills. Nat. Neurosci. 3, 1335-1139.

Genzel, L., Kiefer, T., Renner, L., Wehrle, R., Kluge, M., Grözinger, M., Steiger, A., and Dresler, M. (2012). Sex and modulatory menstrual cycle effects on sleep-related memory consolidation. Psychoneuroendocrinology 37, 987-998.

Golestani, N., Molko, N., Dehaene, S., LeBihan, D., and Pallier, C. (2007). Brain structure predicts the learning of foreign speech sounds. Cereb. Cortex 17, 575-582.

Golestani, N., Paus, T., and Zatorre, R. J. (2002). Anatomical correlates of learning novel speech sounds. Neuron 35, 997-1010.

Golestani, N., and Zatorre, R. J. (2004). Learning new sounds of speech: reallocation of neural substrates. Neuroimage 21, 494-506.

Gottselig, J. M., Hofer-Tinguely, G., Borbély, A. A., Regel, S. J., Landolt, H. P., Rétey, J. V., and Achermann, P. (2004). Sleep and rest facilitate auditory learning. Neuroscience 127, 557-561.

Horne, J. A., and Ostberg, O. (1976). A self-assessment questionnaire to determine morningness-eveningness in human circadian rhythms. Int. J. Chronobiol. 4, 97-110.

Hoonhorst, I., Medina, V., Colin, C., Markessis, E., Radeau, M., Deltenre, P., and Serniclaes, W. (2011). The

\section{ACKNOWLEDGMENTS}

The authors thank Xavier Montana for help in data acquisition. This work was financially supported by FER grant EC9014000007 from Université Libre de Bruxelles to Cécile Colin, by the FRFC grant no. 2.4621.07: "Seeing to hear better: normal and atypical development" to Jacqueline Leybaert. The authors are grateful to René Carré (CNRS researcher at ENST Paris) for providing the speech synthesis software.

development of categorical perception: comparisons between voicing, colors and facial expressions. Speech Commun. 53, 417-430.

Hotermans, C., Peigneux, P., Maertens de Noordhout, A., Moonen, G., and Maquet, P. (2006). Early boost and slow consolidation in motor skill learning. Learn. Mem. 13, 580-583.

Jamieson, D. G., and Morosan, D. E. (1986). Training non-native speech contrasts in adults: acquisition of the English /delta/-/theta/ contrast by francophones. Percept. Psychophys. 40, 205-215.

Johns, M. W. (1991). A new method for measuring daytime sleepiness: the Epworth sleepiness scale. Sleep 14, 50-55.

Karni, A., Tanne, D., Rubenstein, B. S., Askenasy, J. J. M., and Sagi, D. (1994). Dependence on REM sleep of overnight perceptual skill. Science 265, 679-682.

Klatt, D. H. (1980). Software for a cascade/parallel formant synthesizer. $J$. Acoust. Soc. Am. 67, 971-995.

Krupp, L. B., Larocca, N. G., Muir-Nash, J., and Steinberg, A. D. (1989). The fatigue severity scale: application to patients with multiple sclerosis and systemic lupus erythematosus. Arch. Neurol. 46, 1121-1123.

Lisker, L., and Abramson, A. S. (1964). A cross-language study of voicing in initial stops: acoustical measurements. Word 20, 384-422.

Maquet, P., Laureys, S., Peigneux, P., Fuchs, S., Petiau, C., Phillips, C., Aerts, J., Del Fiore Degueldre, C., Meulemans, T., Luxen, A., Franck, G., Van Der Linden, M., Smith, C., and Cleeremans, A. (2000). Experiencedependent changes in cerebral activation during human sleep. Nat. Neurosci. 3, 831-836.

Maquet, P., Schwartz, S., Passingham, R., and Frith, C. (2003). Sleeprelated consolidation of a visuomotor skill: brain mechanisms as assessed by functional magnetic resonance imaging. J. Neurosci. 23, 1432-1440.

Maye, J., Weiss, D. J., and Aslin, R. N. (2008). Statistical phonetic learning in infants: facilitation and feature generalization. Dev. Sci. 11, 122-134.

Maye, J., Werker, J. F., and Gerken, L. (2002). Infant sensitivity to distributional information can affect phonetic discrimination. Cognition 82, B101-B111.

McClaskey, C. L., Pisoni, D. B., and Carrell, T. D. (1983). Transfer of training of a new linguistic contrast in voicing. Percept. Psychophys. 34, 323-330.

Medina, V., Hoonhorst, I., Bogliotti, C., and Serniclaes, W. (2010). Development of voicing perception in French: comparing adults, adolescents and children. J. Phonetics 38, 493-503.

Oldfield, R. C. (1971). The assessment and analysis of handedness: the Edinburgh inventory. Neuropsychologia 9, 97-113.

Orban, P., Rauchs, G., Balteau, E., Degueldre, C., Luxen, A., Maquet, P., and Peigneux, P. (2006). Sleep after spatial learning promotes covert reorganization of brain activity. Proc. Natl. Acad. Sci. U.S.A. 103, 7124-7129.

Peigneux, P., Destrebecqz, A., Hotermans, C., and Cleeremans, A. (2005). Filling one gap by creating another one: memory stabilization is not allor-nothing either. Commentary on Walker MP, A refined model of sleep and the time course of memory formation. Behav. Brain Sci. 28, 78.

Peigneux, P., Laureys, S., Fuchs, S., Destrebecqz, A., Collette, F., Delbeuck, X., Phillips, C., Aerts, J., Del Fiore, G., Degueldre, C., Luxen, A., Cleeremans, A., and Maquet, P. (2003). Learned material content and acquisition level modulate cerebral reactivation during posttraining rapid-eye-movements sleep. $\mathrm{Neu}$ roimage 20, 125-134.

Peigneux, P., and Smith, C. (2010). "Memory processing in relation to sleep," in Principles and Practice of Sleep Medicine, ed. M. Kryger (Philadelphia: Elsevier), 335-347.

Plihal, W., and Born, J. (1997). Effects of early and late nocturnal sleep on declarative and procedural memory. J. Cogn. Neurosci. 9, 534-547. 
Plihal, W., and Born, J. (1999). Effects of early and late nocturnal sleep on priming and spatial memory. Psychophysiology 36, 571-582.

Rauchs, G., Orban, P., Schmidt, C., Albouy, G., Balteau, E., Degueldre, C., Schnackers, C., Sterpenich, V., Tinguely, G., Luxen, A., Maquet, P., and Peigneux, P. (2008). Sleep modulates the neural substrates of both spatial and contextual memory consolidation. PLoS ONE 3, e2949. doi:10.1371/journal.pone.0002949

Roth, D. A., Kishon-Rabin, L., Hildesheimer, M., and Karni, A. (2005). A latent consolidation phase in auditory identification learning: time in the awake state is sufficient. Learn. Mem. 12, 159-164.

Sambeth, A., Ruohio, K., Alku, P., Fellman, V., and Huotilainen, M. (2008). Sleeping newborns extract prosody from continuous speech. Clin. Neurophysiol. 119, 332-341.

Schmidt, C., Collette, F., Cajochen, C., and Peigneux, P. (2007). A time to think: circadian rhythms in human cognition. Cogn. Neuropsychol. 24, 755-789.
Serniclaes, W. (2011). "Features are phonological transforms of natural boundaries," in Cognitive, Physical and Developmental Bases of Distinctive Speech Categories, eds G. N. Clements and R. Ridouane (London: John Benjamins), 237-257.

Smith, C., and MacNeill, C. (1994). Impaired motor memory for a pursuit rotor task following Stage 2 sleep loss in college students. J. Sleep Res. 3, 206-213.

Sterpenich, V., Albouy, G., Darsaud, A., Schmidt, C., Vandewalle, G., Dang Vu, T. T., Desseilles, M. Phillips, C., Degueldre, C., Balteau, E., Colette, F., Luxen, A., and Maquet, P. (2009). Sleep promotes the neural reorganization of remote emotional memory. J. Neurosci. 29, 5143-5152.

Stickgold, R., James, L., and Hobson, J. A. (2000a). Visual discrimination learning requires sleep after training. Nat. Neurosci. 3, 1237-1238.

Stickgold, R., Whidbee, D., Schirmer, B., Patel, V., and Hobson, J. A. (2000b). Visual discrimination task improvement: a multi-step process occurring during sleep. J. Cogn. Neurosci. 12, 246-254.
Tremblay, K., Kraus, N., McGee, T., Ponton, C., and Otis, B. (2001). Central auditory plasticity: changes in the N1-P2 complex after speechsound training. Ear Hear. 22, 79-90.

Tremblay, K. L., Kraus, N., Carrell, T. D., and McGee, T. (1997). Central auditory system plasticity: generalization to novel stimuli following listening training. J. Acoust. Soc. Am. 102, 3762-3773.

Tremblay, K. L., Kraus, N., and McGee, T. (1998). The time course of auditory perceptual learning: neurophysiological changes during speech-sound training. Neuroreport 9, 3557-3560

Wagner, U., Gais, S., Haider, H., Verleger, R., and Born, J. (2004). Sleep inspires insight. Nature 427 352-355.

Walker, M. P., Brakefield, T., Morgan, A., Hobson, J. A., and Stickgold, R. (2002). Practice with sleep makes perfect: sleep-dependent motor skill learning. Neuron 35, 205-211.

Walker, M. P., Brakefield, T., Seidman, J., Morgan, A., Hobson, J. A., and Stickgold, R. (2003). Sleep and the time course of motor skill learning. Learn. Mem. 10, 275-284.

Conflict of Interest Statement: The authors declare that the research was conducted in the absence of any commercial or financial relationships that could be construed as a potential conflict of interest.

Received: 27 March 2012; paper pending published: 22 April 2012; accepted: 30 May 2012; published online: 20 June 2012.

Citation: Collet G, Schmitz R, Urbain $C$, Leybaert J, Colin $C$ and Peigneux $P$ (2012) Sleep may not benefit learning new phonological categories. Front. Neur. 3:97. doi: 10.3389/fneur.2012.00097

This article was submitted to Frontiers in Sleep and Chronobiology, a specialty of Frontiers in Neurology.

Copyright (c) 2012 Collet, Schmitz, Urbain, Leybaert, Colin and Peigneux.

This is an open-access article distributed under the terms of the Creative Commons Attribution Non Commercial License, which permits non-commercial use, distribution, and reproduction in other forums, provided the original authors and source are credited. 